\title{
El Photoshop en guerra: algo más que un retoque cosmético
}

María José Bórquez *

Resumen: Los medios de comunicación suministran hoy en día la parte esencial de la materia partiendo de la cual los individuos estructuran su singularidad. Dentro de esta materia la imagen fotográfíca cumple una función fundamental. Es cierto que, desde su invención en el siglo XIX, ésta nunca funcionó como espejo o reflejo de una realidad particular y que su manipulación antecede largamente a la era digital, pero las posibilidades de "arreglar" o trastocar electrónicamente las imágenes son hoy mayores que nunca, por no decir casi ilimitadas.

Esto no niega que existan ciertos límites en el uso de herramientas de edición como el PhotoShop que parecerían estar dados por ciertos ámbitos de aplicación. No es lo mismo el retoque en moda o en publicidad para borrar arrugas o imperfecciones físicas que en fotos testimoniales de contiendas bélicas para incrementar, por ejemplo, una humareda. Claro ejemplo de esto constituye la intervención que un fotógrafo de la agencia inglesa Reuters realizó sobre una foto suscitando un escándalo de tal magnitud que terminó con su despido. Todo esto demuestra que el Photoshop es mucho más que un mero retoque cosmético.

Palabras clave: imagen digital - fotografía - Photoshop.

[Resúmenes en inglés y portugués en la página 37]

${ }^{(*)}$ Maestranda en Comunicación y Cultura (UBA). Diplomada en Ciencias Sociales con mención en Educación, imágenes y medios (FLACSO). Licenciada en Ciencias de la Comunicación con orientación en Periodismo (UBA). Profesora de Enseñanza Media y Superior en Ciencias de la Comunicación (UBA). Docente de la Carrera de Ciencias de la Comunicación (UBA).

En su libro La construcción de la noticia, Miquel Rodrigo Alsina (1993) dice que se pueden resumir las definiciones de la misma a partir de dos grandes grupos. El primero es el que concibe a la noticia como espejo o reflejo de la realidad, partiendo de la objetividad como clave de la actividad periodística. Desde esta perspectiva, una noticia es potencialmente verdadera desde el momento en que puede espejar o reflejar lo que sucede.

El segundo grupo es el que concibe a la noticia como una construcción discursiva de la realidad que hace un medio masivo de comunicación sobre un acontecimiento. Esta cons- 
trucción nunca puede ser verdadera, sino verosímil. Esto es, según el diccionario de la Real Academia Española, "que tiene apariencia de verdadero, creíble por no ofrecer carácter alguno de falsedad".

La definición de noticia que propone Alsina (1993, p. 185) se inscribe en este último grupo en tanto la conceptualiza como una "representación social de la realidad cotidiana producida institucionalmente que se manifiesta en la construcción de un mundo posible". Los individuos aprehenden su entorno a través de representaciones que implican una actividad de reproducción de las propiedades de los objetos, reproducción entendida no como imitación ni mera copia de una realidad externa, sino como un remodelado, una construcción mental del objeto. En cuanto a la producción institucional hay que decir que la noticia es producto de una organización compleja y que el periodista posee un rol socialmente institucionalizado que lo legitima para llevar adelante su actividad. El mundo posible, por su parte, es el mundo narrativo construido por el periodista a partir de otros dos mundos: el real (universo de los acontecimientos) y el de referencia (contextos en que se puede encuadrar el acontecimiento acaecido).

En cuanto a la diferencia entre estos dos grupos de definiciones de noticia (el tradicional, como espejo; y el de construcción donde se estudia la actividad de los informadores y de las organizaciones de los medios), hay que decir que la misma puede ser útil para analizar el escándalo que se suscitó por la intervención que realizó un fotógrafo de la agencia inglesa Reuters sobre una fotografía de guerra a través del Photoshop ${ }^{1}$. No hay que olvidar, en este sentido, que la edición o montaje es no sólo una herramienta técnica, un proceso mecánico que consiste en empalmar o yuxtaponer planos tomando decisiones acerca del punto de corte, la forma y velocidad de esta transición, el orden de tomas, su duración, etc. La edición también tiene funciones de tipo prácticas y artísticas, lo que conlleva determinados efectos narrativos, de sentido, y emocionales. La edición, según Gerald Millerson (1990), puede trasladar el centro de interés y re-dirigir la atención a otro aspecto de la escena filmada o grabada, puede dar énfasis a una información u omitirla, puede yuxtaponer hechos que ocurren en tiempos y lugares diferentes, puede crear relaciones que no han existido, puede modificar todo el significado de una acción en un instante.

Ahora, y tal como se verá a lo largo de este artículo, si se habla de límites en el uso de herramientas de edición o montaje parecería ser que ese límite está dado, en algunas ocasiones, por los ámbitos de aplicación de estas herramientas. Esto es, estaría permitido el retoque en moda o en publicidad para borrar arrugas o imperfecciones físicas, pero no en guerras. Entonces, y volviendo a las definiciones de noticia de las que se habló al comienzo, ¿se supone que si no se hubiera realizado un retoque en la humareda, incrementando y oscureciendo el humo tras el estallido del misil israelí sobre territorio del Líbano, se hubiera accedido a la "verdad" de lo sucedido? ¿Sería, en ese caso, la foto un fiel reflejo de la realidad? ¿O sería una determinada construcción que se hizo de un acontecimiento particular? Ernst Gombrich (citado por Jacques Aumont en La Imagen,1992) y Jaime García Barroso (1987) son dos autores que pueden contribuir para empezar a responder estas preguntas. En Arte e ilusión Gombrich presenta como su tesis central el hecho de que toda representación es convencional, incluso la más analógica. Sólo los espejos naturales funcionan como puros espejos: "la imitación deliberada, humana, de la naturaleza, implica siempre 
un deseo de creación concomitante con el deseo de reproducción (y que a menudo lo precede)" (Aumont, 1992).

Por su parte García Barroso (1987), en su texto "Tratamiento de la información en televisión", sostiene que dos de los elementos a considerar en el análisis de un plano son el marco y el encuadre/angulación del mismo. García Barroso (1987) dice que el plano presenta no toda la realidad sino sólo un trozo de ella, y que todo encuadre es una selección del mundo real2.

El fotógrafo profesional Gabriel Valansi, entrevistado por Página/12 en relación a este tema, sostiene que "aún sin mediar ningún truco o montaje, es sabido (pero no aceptado), que de por sí un encuadre es una elección subjetiva de una porción de la realidad, y que sólo expresa la opinión y el punto de vista de quien edita la imagen". Para Valansi, "ni siquiera el fotógrafo es el único dueño del sentido final de la imagen, porque su foto puede ser sometida a reencuadres".

Evidentemente lo que ha tenido lugar, en el caso de la foto de la polémica, es un proceso de semantización: un hecho- como es el estallido de un misil en la masacre de Qana- se incorpora, bajo la forma de significaciones, a los contenidos de un medio de comunicación masivo. Tal como afirma Eliseo Verón (1971), toda semantización es el resultado de dos operaciones realizadas por el emisor del mensaje: la selección dentro de un repertorio de unidades disponibles (el misil, la humareda, etc.) y la combinación de las unidades seleccionadas para formar el mensaje (cómo fue presentada la foto en el medio). El autor español Lorenzo Vilches (1989), en su libro "Manipulación de la información televisiva", también habla de selección cuando dice qué es lo que hacen las cámaras con los acontecimientos, en tanto enfocan ciertas acciones y olvidan otras, encuadran desde un cierto ángulo y no desde otros, etc.

\section{El Photoshop. ¿Sólo un retoque cosmético?}

Ahora, si se supone que ninguna imagen es real ${ }^{3}$, que el mero enfoque ya implica un sesgo, ¿por qué tanto revuelo alrededor de una fotografía? Es cierto que la foto podría haber pasado desapercibida entre el extenso catálogo de imágenes bélicas de Reuters, pero no lo fue: cientos de cibernautas denunciaron el truco y esto llevó a que la fotografía se instalara en el centro de la polémica. Así, para el sitio www.esisrael.org, las dos columnas de humo intenso colaborarían con el terrorismo islámico al intensificar la potencia del impacto. Y no fue sólo esto lo que derivó de la publicación de la foto: se habló de que la superposición de viviendas densifican la población, que la palidez del cielo lleva a imaginar la modificación ambiental que produciría un ataque químico, que el incremento de los amarillos y los rojos en las fachadas de las casas aumenta el pintoresquismo del paisaje atacado y tiende a generar lazos de empatía con el agredido, etc. Roland Barthes (1982) seguramente se sumaría a esta última apreciación ya que en su obra "La cámara lúcida" se observa que al autor francés no le gusta demasiado el color en la imagen fotográfica. Barthes cree que: 
en toda fotografía el color es una capa fijada ulteriormente sobre la verdad original del Blanco y Negro. El Color es para mí un postizo, un afeite (...) lo que me importa no es la 'vida' de la foto, sino la certeza de que el cuerpo fotografiado me toca con sus propios rayos, y no con una luz sobreañadida (Barthes, 1982, p. 128).

Pero además de las opiniones antes expuestas y del parecer de Barthes (1982), hay que decir que el truco le costó el puesto al fotógrafo Adrián Hajj que fue acusado de "uso erróneo de software de edición de fotografías", además de sacarle de circulación más de 900 fotos sospechadas.

Diego Levy, otro fotógrafo entrevistado por Página/12, considera que la manipulación de imágenes nunca tiene usos legítimos, ni siquiera - dice Levy- cuándo sólo se trata de achicarle las caderas a una "diva" como Susana Giménez. Para Levy, el uso del Photoshop ha sido la gran revolución de los últimos tiempos en fotografía, pero la mala utilización del mismo es imperdonable, sobre todo en periodismo, ya que modificar o alterar una imagen es manipular al lector.

Claro que la manipulación puede entenderse en dos sentidos diferentes. Puede concebirse como una operación intencional a través de la cual se busca engañar, ocultando, omitiendo o exagerando determinada información con la idea de que se imponga un determinado punto de vista por parte del emisor. O puede entenderse la manipulación como la entiende Vilches (1989). Según este autor, que trabaja desde una perspectiva semiótica, se debe despojar a la manipulación de su carácter demoníaco o perverso en tanto es una operación textual que se realiza en todo acto comunicativo desde el momento en que una cámara se emplaza de un determinado modo; sea televisión, cine o fotografía. Y es una operación textual porque la "realidad" se ve convertida en un texto.

Si uno se atiene a lo que efectivamente sucedió con este fotógrafo y con esta foto en particular parecería imponerse, casi sin discusión, el primer sentido sobre el segundo.

El diario El País, uno de los más importantes de España, prohíbe en su manual de estilo "toda manipulación de las fotografías que no sea estrictamente técnica (edición periodística, eliminación de deterioros o corrección de defectos de revelado). Por tanto no se puede invertir una fotografía, ya se trate de paisajes, edificios o personas".

Lo que es innegable es que, tal como señala Susan Sontag (2000), la manipulación de la fotografía antecede largamente a la era digital y a los trucos del PhotoShop en tanto siempre ha sido posible que una imagen fotográfíca -por ejemplo a través de medios auxiliares como los aumentos que hacen patentes ciertas cosas al tiempo que ocultan otras- tergiverse las cosas. De todas formas, Sontag (2000) reconoce que las posibilidades de arreglar o manipular electrónicamente las imágenes son hoy mayores que nunca, por no decir casi ilimitadas.

Todo lo antes dicho demuestra una vez más que la edición mediante una técnica como el Photoshop es más, mucho más, que un mero retoque cosmético. 


\section{La fotografía polémica como fotografía testimonial}

Tal como sostiene Verón (1997) en De la imagen semiológica a las discursividades, los medios de comunicación suministran hoy en día la parte esencial de la materia partiendo de la cual los individuos estructuran su singularidad. Dentro de esta materia la fotografía, en sus múltiples formas ${ }^{4}$, cumple una función fundamental.

Aparentemente, la fotografía de la polémica puede inscribirse dentro de una de las figuras propias de la imagen fotográfica mediatizada en la prensa escrita de las que habla Verón (1997): la fotografía testimonial. Ésta capta el instante del evento, es siempre instantánea, $y$ en el momento en que se consume por primera vez esa imagen es presente puro, el haber estado allí de hace sólo algunas horas o algunos días. La fotografía es una huella del mundo real en tanto nunca se puede negar que la cosa estuvo allí. Por lo menos así fue entendida desde su invención en el siglo XIX.

Ahora, ¿qué sucede con las cada vez mayores posibilidades de manipulación de la imagen fotográfica mediante medios digitales? ¿Podrá seguirse hablando de una fotografía testimonial, de una fotografía que sirve como testimonio de algo que ocurrió?

Lo cierto es que si es posible poner en duda la juventud de una persona o la cantidad de asistentes a una manifestación, el pacto de credibilidad del que hablaba Barthes (1982) en La cámara lúcida va perdiendo fuerza. Así, la imagen parece estar dejando de ser depósito y certificado de verdad.

Jean-Marie Schaeffer (1990) también aborda esta cuestión de la credibilidad en La imagen precaria. Para Schaeffer (1990) el poder de convicción de una fotografía, su carácter de verdad, depende del saber que tiene el espectador sobre la génesis de esta imagen. Schaeffer (1990) llama a este saber, el saber del arché. Porque sabemos que la imagen fotográfica es una marca, una huella producida por procedimientos físico-químicos es por lo que creemos que representa "adecuadamente" la realidad y estamos dispuestos a creer que dice la "verdad" sobre ella. Lo cierto es que hoy en día muchas personas son conscientes del uso- y en algunos casos, abuso- que se hace del Photoshop en la prensa gráfica.

El fotógrafo argentino Gabriel Machado dice: "no nos pasamos de la raya, no cambiamos los rasgos ni los hacemos de porcelana". Y "el pasarse de la raya" se condena. Esto es lo que le sucedió a Hajj. José Cicala, otro fotógrafo argentino entrevistado por Página/12, sostiene: "está mal hecho cuando te das cuenta de que está truchado: no lo creés (otra vez la cuestión de la credibilidad). Son cosas irracionales, sin razón de ser".

Se habla mucho de que la actual es una civilización de la imagen, de que en el mundo contemporáneo hay una proliferación sin antecedentes de imágenes, lo que ha llevado a su banalización y a su consumo acrítico, desenfrenado, indiscriminado. Pero lo cierto es que en casos como el de la foto controvertida se observa que las imágenes, pese a su innegable proliferación, siguen causando impacto y provocando debates varios y variados. 


\section{Lo que pincha en esta foto y las funciones de la imagen}

Para Barthes (1982) la percepción de una fotografía posee dos instancias: el stadium, que es la visión de la información general de la imagen, una observación de tipo macro; y el punctum, que es la visión de un detalle, de un objeto parcial que fascina al espectador punzándolo, dice él, como una flecha.

Barthes (1982) sostiene que no sólo creemos en la foto, en la realidad que ésta representa, sino que la foto produce una verdadera revelación sobre el objeto representado. La foto hace ver una realidad escenificada -en este caso, un misil que estalla poderosamente en territorio libanés-, pero también hace ver un algo fotográfico en estado puro que provoca al espectador. En esta fotografía en particular, ¿estaría dado por el misil? Tal vez sí. Lo cierto es que en la percepción de esta fotografía que suscitó una gran discusión, llegando a provocar el despido del fotógrafo que la había tomado, hubo algo que no pasó desapercibido, que provocó a su espectador al punto de que cientos de cibernautas denunciaron el truco, y a partir de eso se tejieron las mil y una suposiciones acerca de lo que una fotografía de estas características podría simbolizar e incitar.

Aumont (1992), autor francés contemporáneo que se dedicó a estudiar la imagen cinematográfica, dice que una de las razones por las que se producen las imágenes deriva de la pertenencia de éstas al campo de lo simbólico. La imagen se "sitúa como mediación entre el espectador y la realidad" (Aumont, 1992, p. 82), se constituye como sustituto de lo que representa. Pero para Aumont (1992) la imagen no sólo tiene una función simbólica, sino también imitativa/mimética, epistémica y estética. Imitativa en tanto reconocer algo en una imagen es identificar lo que se ve en ella con algo que se ve o podría verse en la realidad. Epistémica en tanto la imagen aporta informaciones visuales sobre el mundo, transmite un cierto saber acerca de éste; y estética en tanto "la imagen está destinada a complacer a su espectador, a proporcionarle sensaciones específicas" (Aumont, 1992, p. 85).

Es, definitivamente, la función imitativa la más cuestionada hoy en día. Cada vez se pone más en duda que lo que se ve en el interior de una fotografía puede verse en su exterior, o sea, en la realidad.

\section{Algunas palabras a título de (provisorias) conclusiones}

Para ir finalizando se puede retomar una pregunta que ya apareció en este artículo: ¿por qué tanto revuelo alrededor de una fotografía? El más común de los sentidos dice: "Una imagen vale más que mil palabras”. Pero se puede ir más allá.

Aumont (1992, p. 82) afirma en su libro que "la producción de imágenes nunca es absolutamente gratuita $y$, en todos los tiempos, se han fabricado las imágenes con vistas a 
ciertos empleos, individuales o colectivos". Las imágenes tienen o cumplen con determinadas funciones (simbólicas, epistémicas, estéticas), no son meros objetos decorativos u ornamentales.

Por otro lado, Susan Sontag (2004), en su artículo Imágenes torturadas, dice que las fotografías ejercen un poder incomparable en cuanto a lo que recordamos de los acontecimientos. La fotografía es el principal medio moderno de ampliación del mundo y, a diferencia de la palabra escrita, es más difícil de encubrir y de olvidar. Aparte de esto, para la escritora estadounidense hubo un cambio en el uso que se hace de las imágenes, que son menos objetos de conservación que mensajes que han de circular y difundirse. Y al circular y difundirse más alcanzan a más personas y los efectos que pueden llegar a provocar son mayores. Por otro lado, hay que decir que la fotografía nunca funciona como espejo o reflejo de una realidad particular, que la imagen fotográfica no puede ser jamás la mera transparencia de lo sucedido sino que es, tal como sostiene Sontag (2004), "antes que nada, una manera de mirar. No es la mirada misma”. Fotografiar es encuadrar y encuadrar es elegir y es excluir. La imagen fotográfica que se muestra siempre es la imagen que eligió alguien (su autor) para algo, es su punto de vista, no constituye de ninguna manera una ventana abierta al mundo. En suma, es una construcción por lo que el acceso a una verdad última es imposible.

Ahora, esta evidencia no debería esgrimirse como excusa para hacer un uso desaprensivo e irresponsable de las modernas herramientas de edición con que cuenta hoy la fotografía. Se sabe, como se dijo en los inicios de este trabajo, que la edición no es sólo un proceso técnico ni sólo tiene funciones prácticas como omitir fragmentos erróneos o confusos, sino que produce además determinados efectos de sentido. La relevancia de éstos, como pudo observarse, no parece ser la misma si se habla de meros retoques cosméticos publicitarios o de moda a si se habla de fotos testimoniales de contiendas bélicas.

En la introducción de Outside la escritora francesa Marguerite Duras declara:

No hay periodismo sin moral. Todo periodista es un moralista. Es absolutamente inevitable. Un periodista es alguien que mira el mundo, que lo ofrece para que se vea. No puede llevar a cabo ese trabajo y a la vez no juzgar lo que ve. En otras palabras, la información objetiva es una añagaza total. Es una mentira. No existe el periodismo objetivo, no existe el periodista objetivo. Yo me he liberado de muchos prejuicios, entre ellos éste que a mi juicio es el principal. Creer en la objetividad posible del relato de un acontecimiento (Duras, 1984).

Que el plano presente no toda la realidad sino sólo un trozo de ella; que todo encuadre sea una selección del mundo real, conlleva un proceso de toma de decisiones que se inscribe en una cuestión no solamente estética sino también ética de los emisores de los mensajes. 


\section{Notas}

1. De este escándalo da cuenta el periodista Julián Gorodischer en su artículo Retoque de queda publicado en el diario Página/12 el domingo 20 de agosto de 2006.

2. Aumont denomina como visual a esta función del marco que se caracteriza por separar la imagen de su exterior, por aislar un trozo del campo visual singularizando su percepción, volviéndolo más nítido.

3. La desconfianza hacia las imágenes ha existido desde casi siempre en el pensamiento occidental. Ya desde la época antigua, el filósofo griego Platón y sus discípulos creían que la imagen era, por definición, engañosa y era necesario desprenderse de ella para acceder al concepto, para pensar verdaderamente.

4. Las múltiples formas de la fotografía están dadas, según Verón, por la existencia de fotos testimoniales, poses, fotografías categoriales, etc.

\section{Referencias Bibliográficas}

AA.VV. (1990). Manual de Estilo del diario El País. Madrid: El País.

Alsina, M. (1993). La construcción de la noticia. Barcelona: Paidós.

Aumont, J. (1992). La imagen. Barcelona: Paidós.

Barthes, R. (1982). La cámara lúcida. Buenos Aires: Paidós Comunicación.

Diccionario de la Real Academia Española. Disponible en www.rae.es.

Duras, M. (1984). Outside. Barcelona: Orbis.

García Barroso, J. (1987). Tratamiento de la información en TV. Madrid: Instituto Oficial de Radio y Televisión.

Millerson, G. (1990). Técnicas de realización y producción en televisión. Madrid: Instituto

Oficial de Radio y Televisión.

Shaeffer, J. (1990). La imagen precaria. Madrid: Cátedra.

Sontag, S. (2004). Imágenes torturadas. En Revista Ñ, Diario Clarín. 29 de mayo de 2004. (2000). Ante el dolor de los demás. Buenos Aires: Alfaguara.

Verón, E. (1997). De la imagen semiológica a las discursividades: el tiempo de una fotografía. En Isabel Veyrat-Masson y Daniel Dayan (comps.). Espacios públicos en imágenes. Barcelona: Gedisa.

(1971). Ideología y comunicación de masas: La semantización de la violencia política. En AA.VV. Lenguaje y comunicación social. Buenos Aires: Nueva Visión.

Vilches, L. (1989). Manipulación de la información televisiva. Barcelona: Paidós. 
Summary: Nowadays the media provide the basis material of which individuals structure their uniqueness. Within this area the photographic image plays a key role. It is true that since its invention in the nineteenth century, it never functioned as a mirror or reflection of a particular reality and handling long precedes the digital era, but the chances of "fix" or electronically disrupt the images are greater today than ever, if not almost limitless.

This does not deny that there are certain limits on the use of editing tools like PhotoShop that seem to be given by certain application areas. It is not the same the fashion retouching in advertising or to erase wrinkles or physical imperfections that war testimonial photos to increase, for example, a cloud of smoke. We find a clear example in the photo intervention due to an English photographer of Reuters that caused a scandal of such magnitude that ended with his dismissal. All this shows that Photoshop is much more than a mere cosmetic retouching.

Key words: digital image - photography - Photoshop.

Resumo: Os meios de comunicação fornecem hoje a parte essencial da matéria partindo da quais os indivíduos estruturam sua singularidade. Dentro desta matéria a imagem fotográfica tem uma função fundamental. É certo que desde sua invenção no século XIX ela nunca funcionou como espelho ou reflexo de uma realidade particular e que sua manipulação antecede à era digital, mas as possibilidades de fixar eletronicamente as imagens são hoje maiores que nunca, ou quase ilimitadas.

Existem limites no uso de ferramentas de edição como o Photoshop que pareceram estar dados por certos âmbitos de aplicação. Não é o mesmo o retoque em moda ou em publicidade para apagar rugas ou imperfeições físicas que em fotos testemunhais de contendas bélicas para incrementar, por exemplo, uma fuma. Um exemplo claro é a intervenção que um fotógrafo da agencia inglesa Reuters fiz sobre uma fotografia produzindo um escândalo que culminou com seu despido. Isto demonstra que o photoshop é muito mais que um retoque cosmético.

Palavras chave: fotografia - imagem digital - Photoshop. 